\title{
A note on frequency of A1 and A2 variants of bovine beta-casein locus in Polish Holstein bulls*
}

\author{
S. Kamiński ${ }^{1}$, A. Ruść and A. Cieślińska \\ University of Warmia and Mazury in Olsztyn, Department of Animal Genetics \\ Oczapowskiego 5, 10-718 Olsztyn, Poland
}

(Received 12 October 2005; revised version 6 February 2006; accepted 12 April 2006)

\begin{abstract}
Besides its nutritional value, bovine beta-casein is a source of bioactive peptides called betacasomorphins produced during digestion of raw or processed milk. It was shown that the betacasomorphin 7 originates only from beta-casein variants A1 or B and may be a significant risk factor in human ischemic heart disease, arteriosclerosis, type I diabetes and sudden infant death syndrome. In this study, the frequency of the A1 allele in a sample of Polish Holstein bulls commonly used in artificial insemination (A. I. bulls) was analysed and the potential for production of milk capable of releasing undesirable beta-casomorphin 7 is discussed. Among $143 \mathrm{~A}$. I. bulls, three genotypes were identified (A1/A1, A2/A2, A1/A2) resulting in frequencies of 0.402 and 0.598 , for A1 and A2, respectively. Although, the clinical implications of A1 milk on human health is still under discussion it may be necessary to monitor reproductive bulls and decrease the frequency of allele A1.
\end{abstract}

KEY WORDS: Holstein cattle, beta-casein, polymorphism, casomorphin

\section{INTRODUCTION}

The Bovine beta-casein (CSN2) gene belongs to the cluster of 4 casein genes located on chromosome 6 . There are 12 genetic variants of CSN2, but only 5 occur in Holstein cattle: A1, A2, A3, B and C, the first two being the most common (Roginsky, 2003). In polypeptide chain position 67, His is substituted by Pro, for A1 and A2, respectively. In the gene coding CSN2, G in position 8101 is substituted by A (GenBank M55158). In addition to its nutritional value, beta-casein is a source of bioactive peptides called beta-casomorphins produced

\footnotetext{
${ }^{*}$ Supported by the University of Warmia and Mazury, Project No. 0105-0804

${ }^{1}$ Corresponding author: e-mail: stachel@uwm.edu.pl
} 
during the digestion of raw or processed milk or cheese (Jarmolowska et al., 1999; Roginsky, 2003). It was shown that the beta-casomorphin 7 originates only from beta-casein variants A1 or B (Hartwig et al., 1997) and may be a significant risk factor in human ischemic heart disease, arteriosclerosis, type I diabetes and sudden infant death syndrome (Elliot et al., 1999; Thorsdottir et al., 2000; McLachlan, 2001; Sun et al., 2003; Tailford, 2003).

In Poland, research on the frequency of bovine beta-casein variants in bulls was so far not conducted. In this study, an attempt was made to analyse the frequency of the A1 allele in a sample of Polish Holstein bulls used in artificial insemination.

\section{MATERIAL AND METHODS}

One hundred forty three A. I. Polish Holstein bulls commonly used in artificial insemination between 2002-2004 in central-northern Poland. Bulls were genotyped in CSN2 locus by PCR-RFLP method using primers designed by Lien et al. (1992). Briefly, one commercial straw of semen was used to isolate genomic DNA by the MasterPurePurification Kit (Epicentre). The primers have the following sequences: CASB 122 L - 5'GAGTCGACTGCAGATTTTCAACATCAGTGAGAGTCA GGCCCTG3' CASB 67 R-5'CCTGCAGAATTCTAGTCTATCCCTTCCCTG GGCCCATCG3'.

To produce $261 \mathrm{bp}$ fragment of CSN2 gene the following PCR mix was composed: $0.4 \mu \mathrm{l}$ of the primers $122 \mathrm{~L}$ and $67 \mathrm{R}$, each in concentration of 50 $\mathrm{pmol} / \mu 1,0.7 \mathrm{U}$ of Tfl Polymerase (Epicentre), $1.25 \mu 1$ MaserAmp $20 \times$ PCR buffer (Epicentre), $1.5 \mu \mathrm{l}$ magnesium chloride $(15 \mathrm{mM}), 2.0 \mu \mathrm{l}$ enhancer (Epicentre), about $150 \mathrm{ng}$ of genomic DNA and H20 ad $25 \mu 1$. Samples were amplified in MJ Research thermocycler under the following conditions: $3 \mathrm{~min} / 94^{\circ} \mathrm{C}$ and 35 cycles of $94^{\circ} \mathrm{C} / 25 \mathrm{~s}, 62^{\circ} \mathrm{C} / 25 \mathrm{~s}, 72^{\circ} \mathrm{C} / 25 \mathrm{~s}$.

The yield and specificity of PCR products were evaluated after electrophoresis in 1.5\% agarose gel (Promega) with ethidium bromide. The results were observed, analysed and documented by the use of a Fluor-S Multilmager (Bio-Rad). The PCR products were then digested by with Taq I enzyme to generate restriction fragments and electrophoresed in 2.5\% agarose gel (ApmliSize, BioRad).

\section{RESULTS AND DISCUSSION}

In Figure 1, a typical result of A1/A2 CSN2 genotyping is shown. Among 143 Polish Holstein bulls, three genotypes were identified: A1/A1, A2/A2 and $\mathrm{A} 1 / \mathrm{A} 2$, giving a frequency of 0.402 and 0.598 , for $\mathrm{A} 1$ and $\mathrm{A} 2$, respectively 


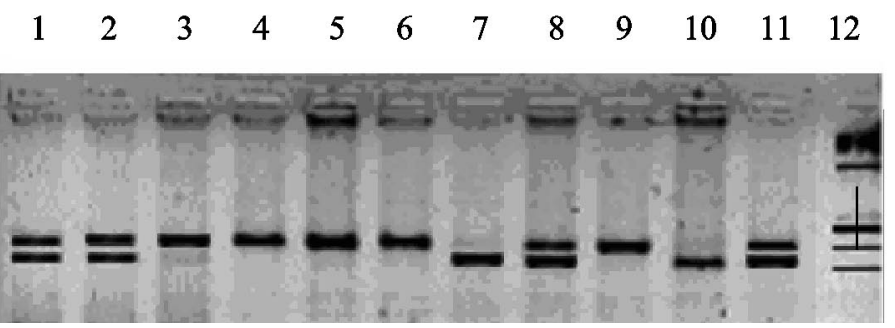

Figure 1. Agarose gel electrophoresis of beta-casein genotypes. Lanes 1, 2, 8, 11 - bulls of A1/A2 genotype. Lanes 3, 5, 9 - bulls of A2/A2 genotype. Lanes 7, 10 - bulls of A1/A1 genotype. Lane 12 - molecular weight marker PhiX 174/Hae III. Restriction fragment $37 \mathrm{bp}$ is not visible on the gel

(Table 1). The frequency of the CSN2 alleles in different breeds and countries is shown in Table 2. This table indicates the general CSN2 allele frequency in

Tabe 1. Frequency of beta-casein A1 and A2 variants in Polish Holstein bulls

\begin{tabular}{lcccc}
\hline $\begin{array}{l}\text { CSN2 } \\
\text { genotype }\end{array}$ & $\begin{array}{c}\text { Number } \\
\text { of bulls }\end{array}$ & $\begin{array}{c}\text { Genotype } \\
\text { frequency, } \%\end{array}$ & \multicolumn{2}{c}{ Frequency of alleles } \\
\hline A1/A1 & 16 & 11.19 & $\mathrm{~A} 1$ & $\mathrm{~A} 2$ \\
$\mathrm{~A} 1 / \mathrm{A} 2$ & 83 & 58.04 & 0.402 & 0.598 \\
A2/A2 & 44 & 30.77 & & \\
\hline
\end{tabular}

Table 2. Occurrence of different beta-casein variants in different breeds and countries

\begin{tabular}{lllll}
\hline \multirow{2}{*}{ Breed } & \multirow{2}{*}{ Country } & \multicolumn{2}{c}{ Frequency of beta-casein alleles } \\
\cline { 3 - 5 } & & \multicolumn{1}{c}{$\mathrm{B}$} & \multicolumn{1}{c}{ A2 } \\
\hline Guernsey & USA & $0.01-0.02$ & $0.01-0.06$ & $0.88-0.97(0.98)$ \\
Jersey & Germany & 0.186 & 0.093 & 0.721 \\
Jersey & Denmark & 0.35 & 0.07 & $0.58-0.65$ \\
Jersey & New Zealand & - & 0.123 & 0.591 \\
Jersey & USA & $0.29-0.37$ & $0.09-0.22$ & $0.49-0.54$ \\
Brown Swedish & Germany & 0.17 & 0.108 & 0.705 \\
Bron Swedish & USA & $0.1-0.18$ & $0.14-0.15$ & $0.66-0.72$ \\
Simmental & Croatia & 0.150 & 0.190 & 0.630 \\
Simmental & Germany & - & 0.343 & 0.566 \\
HF & USA & $0.01-0.06$ & $0.31-0.66$ & $0.24-0.62$ \\
HF & Hungary & 0.051 & 0.456 & $0.449-0.49$ \\
HF & Germany & 0.026 & 0.472 & 0.496 \\
HF & New Zealand & - & 0.465 & 0.510 \\
Black-and-White & Denmark & $0.03-0.08$ & 0.55 & 0.39 \\
Red-and-White & Sweden & 0.008 & 0.46 & 0.531 \\
Red-and-White & Germany & 0.02 & 0.573 & 0.366 \\
Ayrshire & Canada & $0-0.003$ & 0.6 & 0.4 \\
Ayrshire & New Zealand & - & 0.432 & 0.527 \\
Ayrshire & USA & 0 & 0.72 & 0.28 \\
Ayrshire & Finnland & 0.001 & 0.509 & 0.490 \\
Red & Denmark & $0.04-0.06$ & 0.71 & 0.23 \\
\hline
\end{tabular}


Europe: in northern Europe, the dominant allele is A1, but in central and southern Europe its frequency steadily decreases. Also, data published by McLachlan (2001) and Laugesen and Elliott (2003) showed A1 and B alleles frequency in many different countries (about 0.43 ). Our results, for the first time inform about the spread of CSN2 A1 allele and indicate that the frequency of the undesirable allele A1 among Polish Holstein bulls is relatively high (0.41). The population of A.I. bulls is not in genetic equilibrium (A1/A2 genotype is much higher frequent than theoretically expected). This is probably caused by selection pressure in bulls suggesting that this genotype is preferred and probably linked with genes associated with milk performance trait.

Because the method of CSN2 genotyping is based on DNA there is the possibility of fast decreasing the frequency of allele A1 by the monitoring of young and proven bulls and avoiding over-spreading allele A1 through artificial insemination. Including the CSN2 genotype in a breeding program and herd management is a reality in New Zealand. A commercial company A2 Corporation (A2 Corporation, www.a2corporation.com) offers A2 MILK, which is obtained exclusively from cows of the A2/A2 genotype. Although, the clinical implications of A1 milk on human health is still under discussion (Truswell, 2005) and it may be necessary to monitor reproductive bulls and decrease the frequency of allele A1.

\section{REFERENCES}

Elliot R.B., Harris D. P., Hill J.P., Bibby N. J., Wasmuth H.E., 1999. Type I (insulin dependent) diabetes mellitus and cow milk: casein variant consumption. Diabetologia 42, 292-296

Hartwig A., Teschemacher H., Lehmann W., Gauly M., Erhardt G., 1997. Influence of genetic polymorphisms in bovine milk on the occurrence of bioactive peptides. In: Milk Protein Polymorphism. International Dairy Federation. Proceedings of the IDF Seminar, Palmerston (New Zealand), pp. 459-460

Jarmolowska B., Kostyra E., Krawczuk S., Kostyra H., 1999. Beta-casomorphin-7 isolated from Brie cheese. J. Sci. Food Agr. 79, 1788-1792

Laugesen M., Elliott R., 2003. Ischaemic heart disease, type 1 diabetes, and cow milk A1 betacasein. N.Z. Med. J. 116, 1-19

Lien S., Alestrom P., Hungland H., Rogne S., 1992. Detection of multiple beta-casein (CASB) alleles by amplification created restriction sites (ACRS). Anim. Genet. 23, 333-338

McLachlan C.N.S., 2001. Beta-casein A1, ischaemic heart disease mortality, and other illnesses. Med. Hypotheses 56, 262-272

Roginsky H., 2003. Encyclopedia of Dairy Sciences. Academic Press, London

Sun Z., Zhang Z., Wang X., Cade R., Elmer Z., Fregly M., 2003. Relation of beta-casomorphin to apnea in sudden infant death syndrome. Peptides 24, 937-943

Tailford K.A., Brry C.L., Thomas A.C., Campbell J.H., 2003. A casein variant in cow's milk is atherogenic. Atherosclerosis 170, 13-19

Thorsdottir I., Birgisdottir B.E., Johannsdottir I.M., Harris D.P., Hill J., Steingrimsdottir L., Thorsson A.V., 2000. Different (beta-casein) fractions in Icelandic versus Scandinavian cow's milk may influence diabetogenicity of cow's milk in infancy and explain low incidence of insulindependent diabetes mellitus in Iceland. Pediatrics 106, 719-724

Truswell A.S., 2005. The A2 milk case: a critical review. Eur. J. Clin. Nutr. 59, 623-631 